\title{
Yield Components of Triploid and Tetraploid Musa Genotypes in Nigeria
}

\author{
K.P. Baiyeri' ${ }^{1}$, B.N. Mbah ${ }^{1}$, and A. Tenkouano ${ }^{2}$ \\ Crop Improvement Division, International Institute of Tropical Agriculture, \\ PMB 5320, Oyo Road, Ibadan, Nigeria
}

Additional index words. bananas, plantains, genome composition, cropping systems, genotype $\times$ environment interaction, cultivar stability, principal component analysis

\begin{abstract}
The additive main effects and multiplicative interaction (AMMI) model was used to evaluate the stability patterns of 36 Musa genotypes in four cropping environments for bunch weight, pulp weight, and dry matter content. Alleycropping generally induced higher means for all traits than did sole cropping. The triploid plantains produced smaller bunch weights and were less stable than dessert and cooking bananas. In this ploidy group, bunch weight was highest for the cooking bananas 'Cardaba' and 'Fougamou', but only 'Fougamou' was stable across environments. Among the hybrids, only 'FHIA23' (dessert banana) expressed high and stable bunch weights, while other high-yielding hybrids displayed specific adaptation to alleycropping. Pulp weight was lower but more stable in plantains than in other triploid genotypes. Among the hybrids, pulp weight was high and stable for one cooking banana ('FHIA3'), one dessert banana ('FHIA1'), and three plantains ('PITA1', 'PITA2', and 'PITA7'). Dry matter content was highest in plantains and lowest in dessert bananas at both triploid and tetraploid levels, and was also more stable than the other traits. Thus, the adaptation patterns of genotypes across environments varied according to the trait studied. When rank changes were not observed across traits for a given genotype, differences were still noted in the relative magnitude of the IPCA1 score. Hence, both farm gate traits and postharvest processing traits should be considered in selecting for broad or specific adaptation. Determination of the genetic relationships between processing traits and farm gate traits could allow $\mathrm{Musa}$ breeders to construct selection indices that would facilitate multiple trait selection and enhance breeding efficiency, with respect to cultivar stability and adaptation across environments.
\end{abstract}

Bananas and plantains (Musa sp.) are starchy staple crops of considerable economic importance in the developing world (Dadzie and Orchard, 1996; Robinson, 1996). They evolved from inter- and intra-specific crosses between two diploid $(2 \mathrm{n}=2 \mathrm{x}=22)$ species native to southeast Asia, M. acuminata Colla. and M. balbisiana Colla. (Simmonds, 1962). The two species have different genomes, designated as A for M. acuminata and B for $M$. balbisiana. The existing cultivars are distinguished by the number of $\mathrm{A}$ and $\mathrm{B}$ genomes they harbor, e.g., AAA predominantly for dessert bananas, AAB for plantains, and ABB for cooking bananas (Robinson, 1996; Simmonds, 1962; Stover and Simmonds, 1987). For example, genes for parthenocarpy and yield are generally considered to be contributed by the A genome, whereas the $\mathrm{B}$ genome harbors

Received for publication 14 July 1999. Accepted for publication 18 Feb. 2000. This research was supported in part by a grant from the Belgian Administration for Development and Cooperation (BADC). Manuscript no. IITA/99/JA/27. The cost of publishing this paper was defrayed in part by the payment of page charges. Under postal regulations, this paper therefore must be hereby marked advertisement solely to indicate this fact.

${ }^{1}$ Faculty of Agriculture, Univ. of Nigeria, Nsukka, Nigeria.

${ }^{2}$ To whom requests for reprints should be addressed. International mailing address: IITA c/o L.W. Lambourn \& Co., 26 Dingwall Road, Croydon CR9 3EE, England. E-mail address: A.Tenkouano@ satmail.bt.com system, inter-cropping constitutes the predominant mode of cultivation. The challenge facing breeders is to select elite cultivars that will perform well under an alleycropping system, yet be amenable to intensification under a monoculture regime. Such cultivars should not display substantial trait variations over cropping systems. Thus, an understanding of trait stability is important to avoid spurious recommendations (Kang, 1998).

Yield evaluation trials provide yield estimates for each genotype in each environment, based on statistical techniques that detect and partition important agronomic variation into components (Gauch, 1992; Gauch and Furnas, 1991). Additive main effect and multiplicative interaction (AMMI) is ordinarily the model of first choice when both main effects and interactions are significant (Crossa et al., 1990; Mandel, 1971; Zobel et al., 1988). This analytical method has been applied to assess the performance of plantain-banana hybrids with respect to yield (Ortiz, 1998) and response to virus infection (Ortiz, 1996).

The harvested bunches of bananas and plantains often possess a significant proportion of nonedible and nonprocessible parts, which may reduce market potential and consumer acceptance of new cultivars. The concept of marketable yield has been used by potato (Solanum tuberosum L.) breeders to designate the fraction of the production accounted for by tubers that are suitable to consumers based on their weight (Ortiz et al., 1988). Market potential of plantain and banana may also be defined in that way, based on pulp weight of the harvested fruit, dry matter content of the pulp, and shelf-life of the fruit (Baiyeri et al., 1999). Dry matter content may determine the fraction of harvested crop that is available for processing into food products (Sanchez Nieva et al., 1968), i.e., the biological value of the crop. Dry matter content has genes for hardiness, drought tolerance, and increased starchiness (Robinson, 1996).

In West Africa, plantains and bananas are usually grown in backyards or in small forest fields. In the first system, pure stands are grown perennially in plots that receive organic matter from household refuse. In the second
Table 1. Genome and ploidy characteristics of the genotypes used in this study.

\begin{tabular}{lcc}
\hline \hline Classification $^{z}$ & Landraces (3x) & Hybrids $^{y}$ \\
\hline Dessert bananas & Pisang Ceylan (PSC) & FHIA-1 (F01), FHIA-2 (F02), \\
& Valery (VAL) & FHIA-23 (F23), SH3436-9 (S34) \\
Yangambi Km5 (KM5) & SH3640 (S36), EMB 402 (EM2), \\
Plantains & EMB 403 (EM3), EMC 602 (EMC) \\
& Agbagba (AGB) & PITA-1 (P01), PITA-2 (P02), \\
Obino l'Ewai (OBI) & PITA-3 (P03), PITA-5 (P05), \\
UNN.DB (UNN) & PITA-7 (P07), PITA-8 (P08), \\
& & PITA-9 (P09), PITA-11 (P11), \\
Cooking bananas & PITA-12 (P12), PITA-14 (P14), \\
& PITA-16 (P16), FHIA-21 (F21), \\
& FHIA-22 (F22) \\
& Cardaba (CAR) & BITA-1 (BT1), BITA-2 (BT2), \\
& Bougamou, (FOU) & \\
Pelipita (PEL) & \\
Saba (SAB) & \\
\hline
\end{tabular}

${ }^{2}$ Musa cultivars are distinguished by the number of $\mathrm{A}$ and $\mathrm{B}$ genomes they harbor, e.g., AAA predominantly for dessert bananas, AAB for plantains, and ABB for cooking bananas (Robinson, 1996; Simmonds, 1962; Stover and Simmonds, 1987). Dessert banana hybrids are denoted AAA X AA, plantain hybrids AAB x AA, and cooking banana hybrids ABB x AA.

${ }^{y}$ FHIA and SH series are hybrids from Fundaçion Hondureña de Investigacíon Agricóla, Honduras; PITA and BITA series are, respectively, plantain and banana hybrids from the International Institute of Tropical Agriculture, Nigeria; EMB and EMC hybrids are from Empresa Brasileira de Pesquisa Agropecuària (EMBRAPA) and Empresa Capixaba de Pesquisa Agropecuària (EMCAPA) in Brazil, respectively; others are landraces. Note that PITA16 is a triploid while others are tetraploids. The threecharacter codes that appear in parentheses after each genotype are used in Figs. 1-4. 
also been considered an indicator of cooking quality of banana and plantain (Dadzie and Orchard, 1996) and may be positively correlated with storage ability (Ferris et al., 1996). The effects of genotype $\times$ environment (GE) interactions should be assessed not only on yield performance but also on those components that determine the potential market value of the fruits.

The objectives of this study were to determine: 1) the performance of different Musa genotypes across cropping systems; and 2) the effects of genome composition and ploidy level on their phenotypic stability for important yield components.

\section{Materials and Methods}

Thirty-six genotypes representative of cultivated Musa sp. subgroups were studied (Table 1). They included 24 primary tetraploid hybrids, one secondary triploid hybrid, and 11 triploid landraces. The landraces included three plantains, five cooking bananas, and three dessert bananas. All plantain and dessert banana landraces are susceptible to the leaf spot disease black sigatoka (caused by Mycosphaerella fijiensis Morelet), which causes yield losses ranging from $30 \%$ to complete crop failure (Mobambo et al., 1993). The hybrids were obtained by introgressing genes for resistance to black sigatoka from diploid accessions into landraces of plantain (13 hybrids), cooking bananas (four), and dessert bananas (eight). The 36 genotypes were evaluated under sole cropping and alleycropping with multiple species hedgerows at the High Rainfall Station of the International Institute of Tropical Agriculture at Onne (lat. $4^{\circ} 43^{\prime} \mathrm{N}$, long. $7^{\circ} 01^{\prime} \mathrm{E}$, $10 \mathrm{~m}$ altitude above sea level), in southeastern Nigeria. The station is located in a degraded rainforest-swamp characterized by an ultisol derived from coastal sediments and $2400 \mathrm{~mm}$ unimodal annual rainfall. Detailed characteristics of the station have been described elsewhere (Ortiz et al., 1997).

Planting was done on 19 and 20 June 1995 for the sole crop and alleycrop trials, using a 6 $\times 6$ simple lattice design. Each genotype was grown in a single-row plot of five plants per replication and cultural practices were those described by Swennen (1990). Fruits were harvested at round-full stage (disappearance of fruit angularity) or at the onset of ripening of one or two fruits from the proximal end of the bunch, and bunch weight per plant was measured. For each plant, the fruits were detached from the bunch and the pulp was weighed after removal of the fruit peel. The pulp was oven-dried $\left(50{ }^{\circ} \mathrm{C}, 72 \mathrm{~h}\right)$ and dry matter content was determined and expressed as percentage of fresh weight.

Data were collected over two crop cycles for each trial and subjected to analysis of variance (ANOVA) using the MATMODEL version 2 software (Gauch, 1993), based on the following statistical model:

$$
Y_{i j}=\mu+\alpha_{i}+\beta_{j}+(\alpha \beta)_{i j}+\varepsilon_{i j}
$$

where $Y_{\mathrm{ij}}$ is the performance observed for the
Table 2. Means squares from the AMMI2 analysis of some yield characteristics of 36 Musa genotypes grown in four cropping environments in Nigeria.

\begin{tabular}{lrclcc}
\hline $\begin{array}{l}\text { Source of } \\
\text { variation }\end{array}$ & \multicolumn{1}{c}{ df } & \multicolumn{1}{c}{$\begin{array}{c}\text { No. of days } \\
\text { to harvest }\end{array}$} & $\begin{array}{c}\text { Bunch wt } \\
(\mathrm{kg} / \mathrm{plant})^{\mathrm{z}}\end{array}$ & $\begin{array}{c}\text { Pulp fresh wt } \\
(\mathrm{kg} / \mathrm{plant})^{\mathrm{z}}\end{array}$ & $\begin{array}{c}\text { Dry matter } \\
\text { content }(\%)^{\mathrm{z}}\end{array}$ \\
\hline Total & 274 & 35606.23 & 28.18 & 8.38 & 27.53 \\
Treatment & 143 & $60945.44^{* * *}$ & $48.18^{* * *}$ & $13.88^{* * *}$ & $43.43^{* * * *}$ \\
Genotype (G) & 35 & $37254.56(15)^{* * *}$ & $68.36(35)^{* * * *}$ & $17.78(32)^{* * * *}$ & $136.87(77)^{* * *}$ \\
Environment (E) & 3 & $2046475.15(70)^{* * *}$ & $963.71(42)^{* * * *}$ & $267.79(40)^{* * * *}$ & $34.38(2)^{*}$ \\
G $\times$ E & 105 & $12112.99(15)$ & $15.29(23)^{* * *}$ & $5.33(28)^{* * *}$ & $12.55(21)$ \\
IPCA1 & 37 & 14596.62 & $24.20^{* * * *}$ & $8.34^{* * * *}$ & 23.26 \\
IPCA2 & 35 & 7349.08 & $16.43^{* * *}$ & $5.57^{* * * *}$ & 7.18 \\
Residual & 33 & 3168.81 & 4.10 & 1.70 & 6.22 \\
Error & 131 & 10442.99 & 6.35 & 2.38 & 10.03 \\
\hline
\end{tabular}

$\overline{{ }^{*}, * * *} \mathrm{~F}$ test significant at $P \leq 0.05$ and 0.001 levels, respectively. The numbers in parentheses indicate the percentages (\%) of treatment sum of squares accounted for by treatment components.
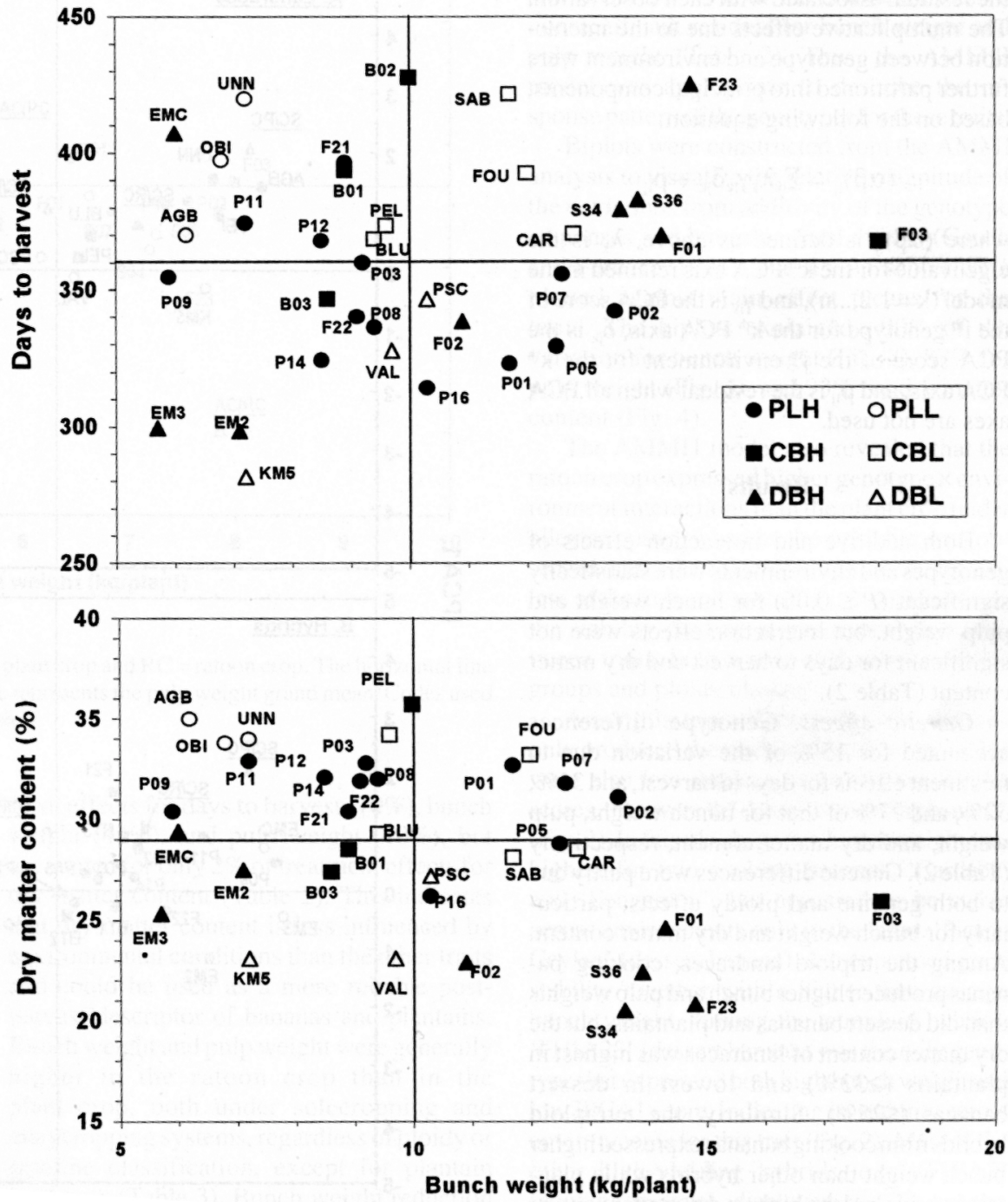

Fig. 1. Relationship between bunch weight and (a) growth cycle and (b) dry matter content in some plantain and banana genotypes in Nigeria. The horizontal lines indicate the mean number of days to harvest and the mean dry matter content respectively in (a) and (b), while the vertical line represents the bunch weight grand mean. Codes used for cultivar or hybrid designation are given in Table 1. PLH $=$ plantain hybrids, $\mathrm{PLL}=$ plantain landraces, $\mathrm{CBH}=$ cooking banana hybrids, $\mathrm{CBL}=$ cooking banana landraces, $\mathrm{DBH}=$ dessert banana hybrids, and $\mathrm{DBL}=$ dessert banana landraces. 
Table 3. Ploidy and genome group effects on bunch weight, pulp weight and dry matter content across four cropping environments in Nigeria.

\begin{tabular}{|c|c|c|c|c|c|c|c|}
\hline \multirow[b]{2}{*}{ Genome group } & \multirow[b]{2}{*}{ Environment $^{2}$} & \multicolumn{2}{|c|}{ Bunch wt (kg/plant) } & \multicolumn{2}{|c|}{ Pulp wt (kg/plant) } & \multicolumn{2}{|c|}{ Dry matter content $(\%)$} \\
\hline & & Landraces & Hybrids & Landraces & Hybrids & Landraces & Hybrids \\
\hline \multirow{4}{*}{ Dessert bananas } & $\mathrm{SC} / \mathrm{PC}$ & $6.0 \pm 1.29^{y}$ & $5.9 \pm 0.85$ & $3.4 \pm 0.84$ & $2.8 \pm 0.44$ & $23.7 \pm 1.18$ & $23.3 \pm 0.89$ \\
\hline & $\mathrm{SC} / \mathrm{RC}$ & $8.8 \pm 0.52$ & $8.1 \pm 0.76$ & $5.3 \pm 0.64$ & $4.0 \pm 0.41$ & $23.7 \pm 1.13$ & $24.0 \pm 0.95$ \\
\hline & $\mathrm{AC} / \mathrm{PC}$ & $7.2 \pm 1.54$ & $12.2 \pm 1.66$ & $3.6 \pm 0.74$ & $6.0 \pm 0.86$ & $25.3 \pm 1.26$ & $24.7 \pm 0.78$ \\
\hline & $\mathrm{AC} / \mathrm{RC}$ & $14.3 \pm 1.16$ & $17.4 \pm 1.28$ & $7.9 \pm 0.85$ & $9.0 \pm 0.65$ & $25.3 \pm 0.99$ & $24.5 \pm 1.01$ \\
\hline \multirow[t]{4}{*}{ Plantains } & $\mathrm{SC} / \mathrm{PC}$ & $5.6 \pm 0.53$ & $6.6 \pm 0.32$ & $3.1 \pm 0.35$ & $3.5 \pm 0.18$ & $33.3 \pm 1.03$ & $32.1 \pm 0.51$ \\
\hline & $\mathrm{SC} / \mathrm{RC}$ & $5.7 \pm 0.75$ & $8.3 \pm 0.57$ & $3.0 \pm 0.38$ & $4.6 \pm 0.38$ & $34.9 \pm 1.03$ & $29.8 \pm 0.60$ \\
\hline & $\mathrm{AC} / \mathrm{PC}$ & $9.3 \pm 1.16$ & $9.5 \pm 0.77$ & $5.2 \pm 0.73$ & $4.9 \pm 0.43$ & $35.2 \pm 1.18$ & $32.5 \pm 0.46$ \\
\hline & $\mathrm{AC} / \mathrm{RC}$ & $6.5 \pm 0.67$ & $14.7 \pm 1.15$ & $3.4 \pm 0.35$ & $7.9 \pm 0.72$ & $34.0 \pm 0.46$ & $30.6 \pm 0.50$ \\
\hline \multirow[t]{4}{*}{ Cooking bananas } & $\mathrm{SC} / \mathrm{PC}$ & $6.6 \pm 0.59$ & $7.5 \pm 1.23$ & $3.4 \pm 0.37$ & $3.5 \pm 0.54$ & $29.9 \pm 1.40$ & $28.3 \pm 1.57$ \\
\hline & $\mathrm{SC} / \mathrm{RC}$ & $10.2 \pm 0.50$ & $10.2 \pm 1.74$ & $5.5 \pm 0.43$ & $4.9 \pm 0.85$ & $30.5 \pm 0.64$ & $26.5 \pm 0.61$ \\
\hline & $\mathrm{AC} / \mathrm{PC}$ & $11.4 \pm 1.39$ & $11.8 \pm 2.14$ & $6.1 \pm 0.85$ & $5.6 \pm 0.93$ & $31.2 \pm 1.22$ & $29.3 \pm 1.62$ \\
\hline & $\mathrm{AC} / \mathrm{RC}$ & $16.1 \pm 1.35$ & $16.7 \pm 2.15$ & $8.5 \pm 0.80$ & $4.9 \pm 0.93$ & $31.2 \pm 0.95$ & $32.5 \pm 5.34$ \\
\hline
\end{tabular}

${ }^{2} \mathrm{AC}=$ alley crop, $\mathrm{SC}=$ sole crop, $\mathrm{PC}=$ plant crop, and $\mathrm{RC}=$ ratoon crop.

${ }^{\mathrm{y}}$ Mean and standard error.

$\mathrm{i}^{\text {th }}$ genotype in the $\mathrm{j}^{\text {th }}$ environment, $\mu$ is the overall mean of the trait, $\alpha_{i}$ is the effect of the $\mathrm{i}^{\text {th }}$ genotype $(\mathrm{i}=1,2, . ., 36), \beta_{\mathrm{j}}$ is the effect of the $\mathrm{j}^{\text {th }}$ environment $(\mathrm{j}=1,2,3,4),(\alpha \beta)_{\mathrm{ij}}$ is the genotype $\times$ environment interaction effect, and $\varepsilon_{\mathrm{ij}}$ is the residual associated with each observation. The multiplicative effects due to the interaction between genotype and environment were further partitioned into principal components, based on the following equation:

$$
(\alpha \beta)_{\mathrm{ij}}=\sum_{\mathrm{k}} \lambda_{\mathrm{k}} \gamma_{\mathrm{ik}} \delta_{\mathrm{jk}}+\rho_{\mathrm{ij}}
$$

where $(\alpha \beta)_{\mathrm{ij}}$ is defined as above, $\lambda_{\mathrm{k}}$ is the eigenvalue for the $\mathrm{k}^{\text {th }}$ PCA axis retained in the model $(\mathrm{k}=1,2, . ., \mathrm{n})$, and $\gamma_{\mathrm{ik}}$ is the PCA score of the $\mathrm{i}^{\text {th }}$ genotype for the $\mathrm{k}^{\text {th }}$ PCA axis, $\delta_{\mathrm{jk}}$ is the PCA score of the $j^{\text {th }}$ environment for the $k^{\text {th }}$ PCA axis, and $\rho_{\mathrm{ij}}$ is the residual when all PCA axes are not used.

\section{Results}

Both additive and interaction effects of genotypes and environments were statistically significant $(P \leq 0.05)$ for bunch weight and pulp weight, but interaction effects were not significant for days to harvest and dry matter content (Table 2).

Genetic effects. Genotype differences accounted for $15 \%$ of the variation due to treatment effects for days to harvest, and $35 \%$, $32 \%$, and $77 \%$ of that for bunch weight, pulp weight, and dry matter content, respectively (Table 2). Genetic differences were partly due to both genome and ploidy effects, particularly for bunch weight and dry matter content. Among the triploid landraces, cooking bananas produced higher bunch and pulp weights than did dessert bananas and plantains, but the dry matter content of landraces was highest in plantains $(\geq 33 \%)$ and lowest in dessert bananas $(\leq 25 \%)$. Similarly, the tetraploid hybrids from cooking bananas expressed higher bunch weight than other hybrids while plantain hybrids had the highest dry matter content (Table 3). Pulp weight did not differ among the genomic groups of the hybrids (Table 3 ). On average, triploid genotypes had higher dry matter content than did tetraploid hybrids. In contrast, tetraploid hybrids displayed greater bunch weight than their triploid counterparts

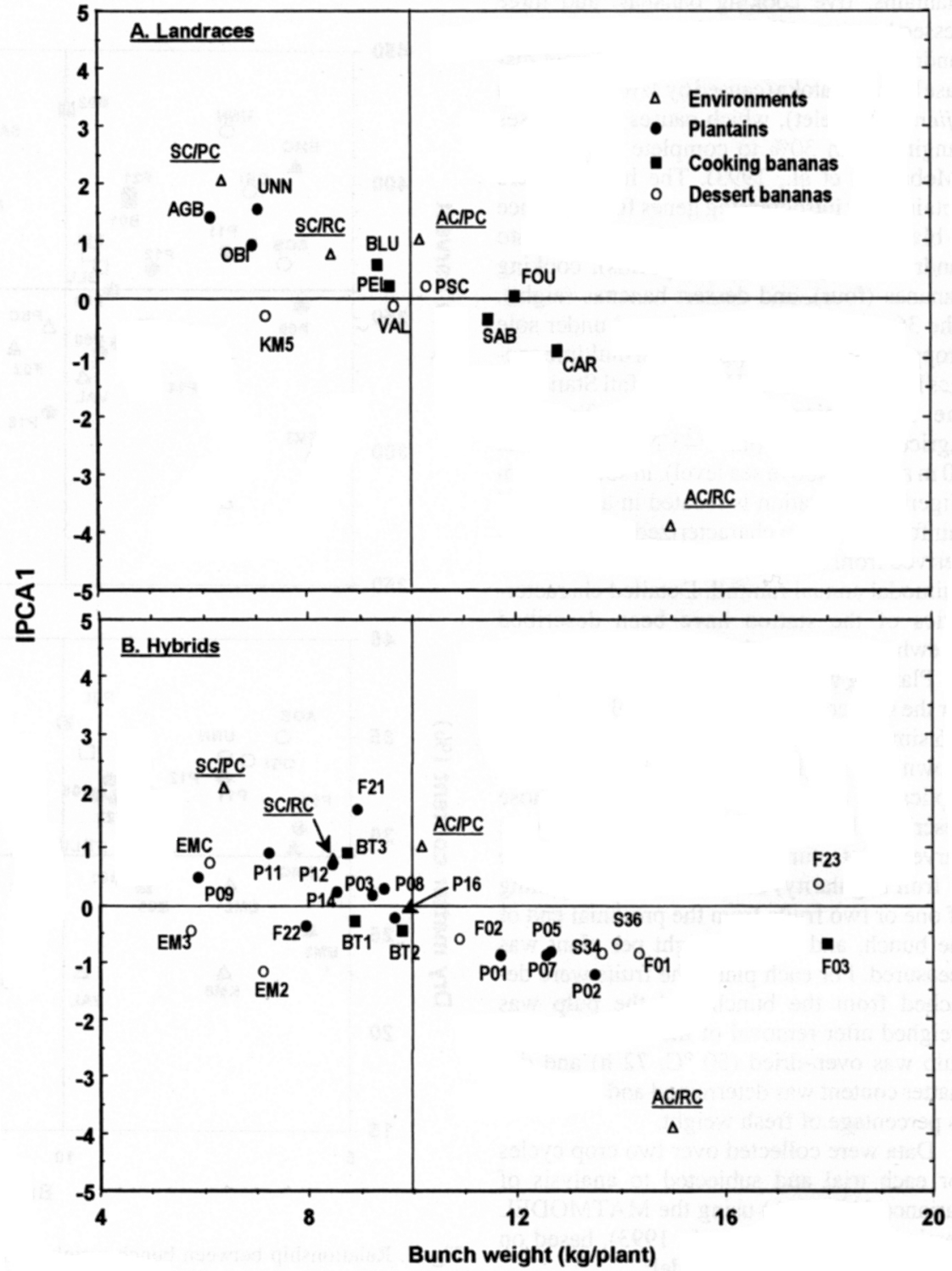

Fig. 2. AMMI1 biplot for bunch weight $(\mathrm{kg} / \mathrm{plant}) . \mathrm{PC}=$ plant crop and $\mathrm{RC}=$ ratoon crop. The horizontal line indicates the zero ICA1 score while the vertical line represents the bunch weight grand mean. Codes used for cultivar or hybrid designation are given in Table 1. 


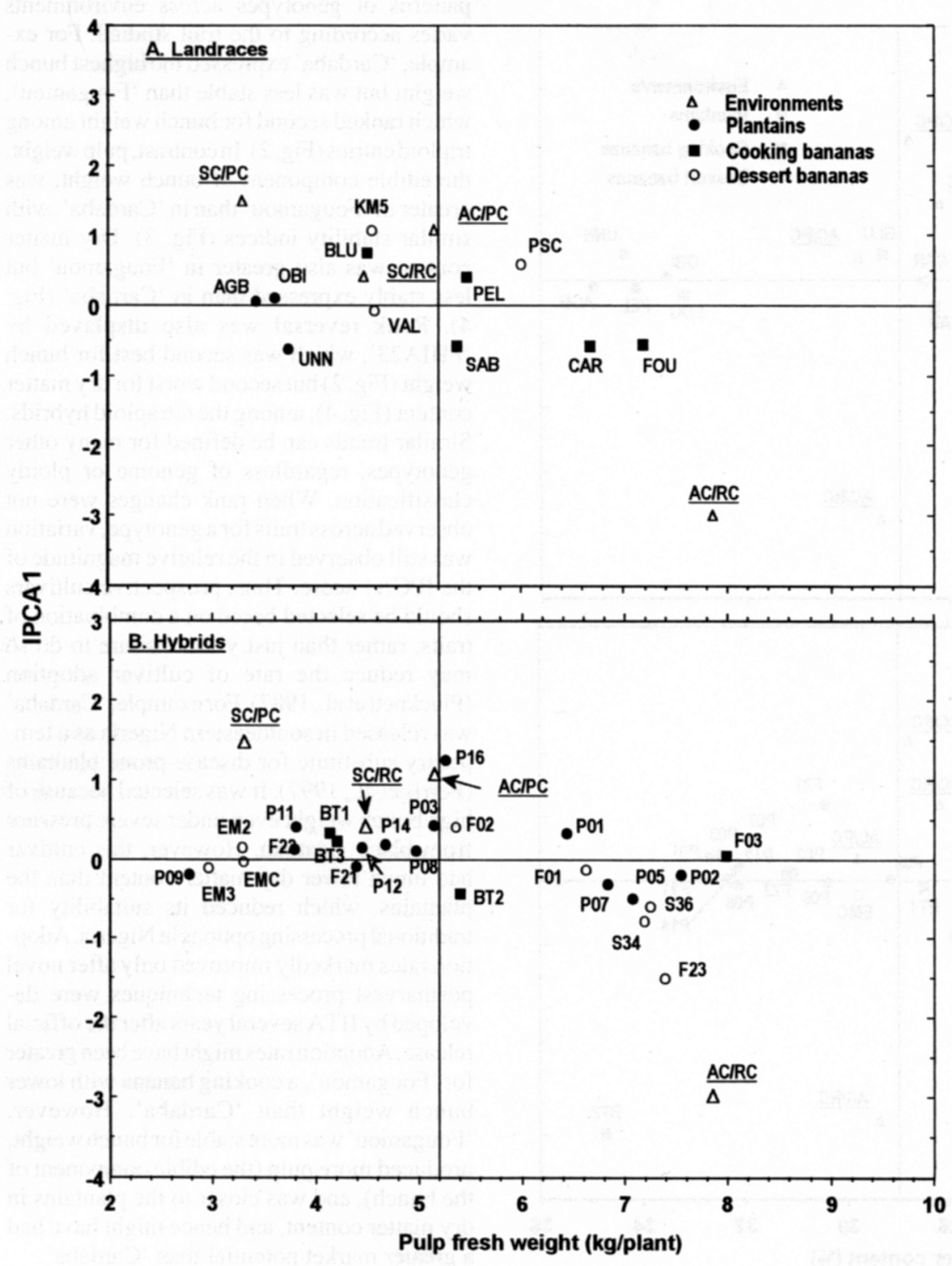

Fig. 3. AMMI1 biplot for pulp weight (kg/plant). $\mathrm{PC}=$ plant crop and $\mathrm{RC}=$ ratoon crop. The horizontal line indicates the zero ICA1 score while the vertical line represents the pulp weight grand mean. Codes used for cultivar or hybrid designation are given in Table 1.

in the dessert banana and plantain groups, but not in the cooking banana group (Table 3). Inter-ploidy differences were less conspicuous for pulp weight and appeared to be influenced by cropping environment, regardless of genome composition (Table 3 ). The cooking banana hybrid 'FHIA3' produced the highest bunch weight per plant, but this was associated with a long growth cycle and a relatively low dry matter content of the fruits (Fig. 1). Similarly, the high yields of the dessert banana hybrids 'FHIA1', 'FHIA23', 'SH3436-9', and 'SH3640' were also coupled with long growth cycles and low dry matter content (Fig. 1). In contrast, several plantain hybrids ('PITA1', 'PITA2', 'PITA5', and 'PITA7') combined high yield with a shorter growth cycle and high dry matter content.

Environmental effects. Environmental factors were the predominant component of treat- alleycropping system is a more resource-rich environment because organic matter build-up, moisture, and nutrient retention are higher (Ruhigwa et al., 1992). The most responsive genotypes were the dessert banana hybrids, with average superiority of more than $100 \%$ for bunch weight and pulp weight in alleycropping vs. monocropping (Table 3 ). The hybrids derived from cooking bananas and plantains also responded positively to improved cropping environment $(<50 \%$ superiority for plantain hybrids, but $>50 \%$ for cooking banana hybrids) (Table 3 ).

Genotype $\times$ environment interaction. The GE interaction accounted for $23 \%$ of the variation for bunch weight and $28 \%$ for pulp weight, but was not statistically significant for days to harvest and dry matter content (Table 2 ). The interaction was mainly attributed to cross-order performance across cropping systems rather than cropping cycles (Table 3 ). Principal component analysis (PCA) identified two significant interaction principal components, IPCA1 (>55\% of interaction effects) and IPCA $2(\approx 35 \%$ of the interaction) and a nonsignificant residual for bunch weight and pulp weight (Table 2). Thus, the AMMI2 model was appropriate to describe the response pattern of the genotypes for these traits.

Biplots were constructed from the AMMI analysis to visualize the relative magnitude of the deviations from additivity of the genotype responses and environmental effects (Gauch and Furnace, 1991). The IPCA1 scores were plotted against main effect means for the traits. The biplots explained $\approx 90 \%$ of the variation for bunch weight (Fig. 2), $87 \%$ for pulp weight (Fig. 3), and $93 \%$ for dry matter content (Fig. 4).

The AMMI1 model also revealed that the ratoon crop expressed higher genotype $\times$ environment interactions than the plant crop under alleycropping, whereas the opposite was observed under the solecropping system, regardless of the trait assessed (Figs. 2-4). However, the stability grading of genotypes varied between traits, both within and across genome groups and ploidy classes.

Among the triploid genotypes, plantains not only produced the smallest bunch weights, but were also less stable, i.e., had higher IPCA1 scores, than were the dessert or cooking bananas (Fig. 2). In this ploidy group, bunch weight was highest for two cooking bananas, 'Cardaba' and 'Fougamou', but appeared to be stable across environments only in the latter. 'Pisang Ceylan' (dessert banana) also expressed good stability together with a higher than average bunch weight. Among the tetraploid hybrids, 'FHIA23' (dessert banana) was the only genotype that expressed both high bunch weight and low IPCA1 score, indicating its stability across environments for this trait (Fig. 2). Most of the other high-yielding hybrids, e.g., 'FHIA3' (cooking banana), displayed specific adaptation to alleycropping. Among the plantain hybrids, 'FHIA21' had the highest IPCA1 score while 'PITA3' had the lowest. However, both hybrids produced smaller than average bunches. Only four ('PITA1', 'PITA2', 'PITA5', and 'PITA7') of the 13 plantain hybrids assessed 


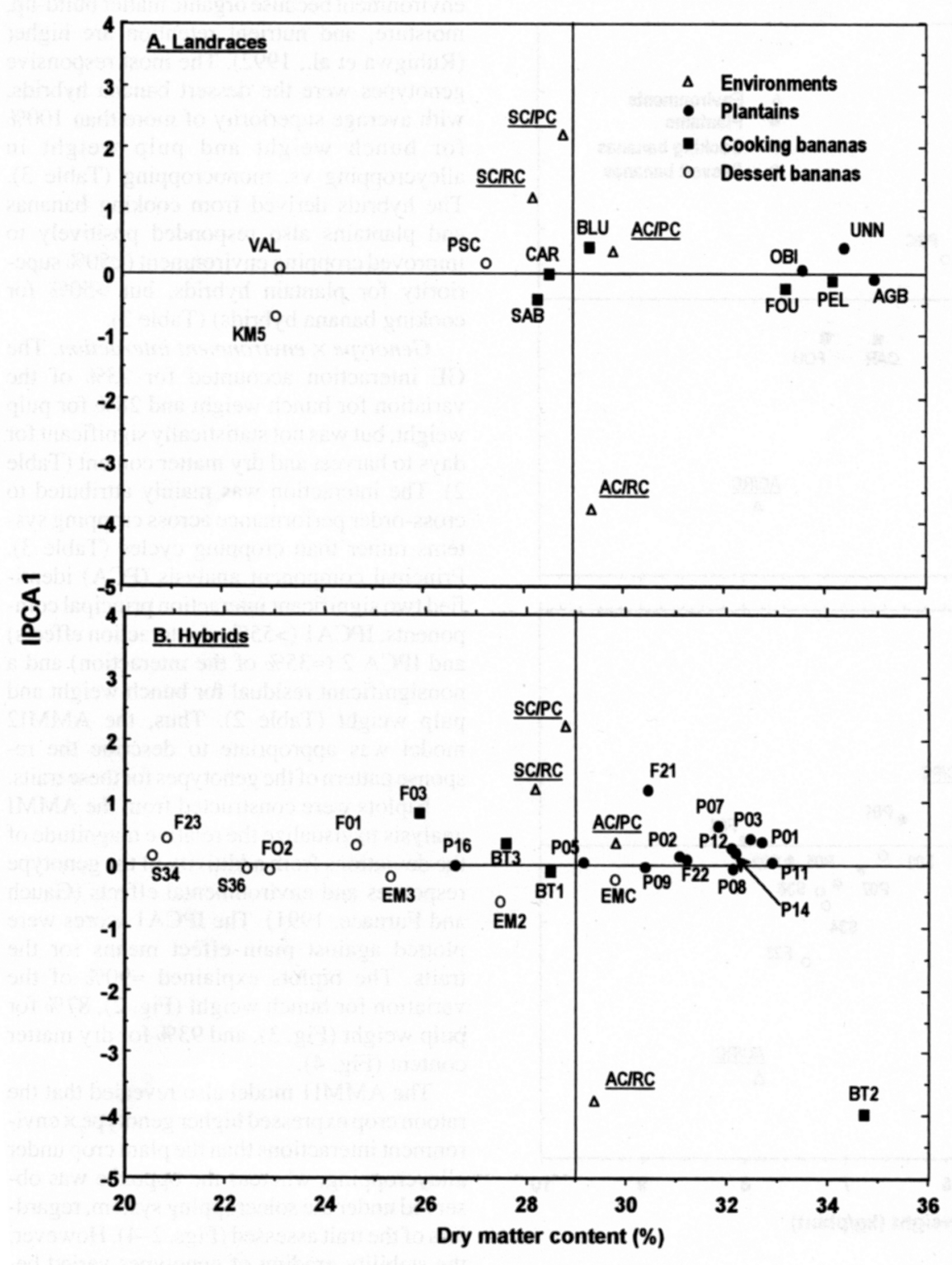

Our study suggests that the adaptation patterns of genotypes across environments varies according to the trait studied. For example, 'Cardaba' expressed the highest bunch weight, but was less stable than 'Fougamou', which ranked second for bunch weight among triploid entries (Fig. 2). In contrast, pulp weight, the edible component of bunch weight, was greater in 'Fougamou' than in 'Cardaba', with similar stability indices (Fig. 3). Dry matter content was also greater in 'Fougamou' but less stably expressed than in 'Cardaba' (Fig. 4). Rank reversal was also displayed by 'FHIA23', which was second best for bunch weight (Fig. 2) but second worst for dry matter content (Fig. 4), among the tetraploid hybrids. Similar trends can be defined for many other genotypes, regardless of genome or ploidy classification. When rank changes were not observed across traits for a genotype, variation was still observed in the relative magnitude of the IPCA1 score. Thus, prospective cultivars should be selected based on a combination of traits, rather than just yield. Failure to do so may reduce the rate of cultivar adoption (Plucknett et al., 1987). For example, 'Cardaba' was released in southeastern Nigeria as a temporary substitute for disease-prone plantains (Ferris et al., 1997). It was selected because of high bunch weight even under severe pressure from black sigatoka. However, this cultivar had much lower dry matter content than the plantains, which reduced its suitability for traditional processing options in Nigeria. Adoption rates markedly improved only after novel postharvest processing techniques were developed by IITA several years after the official release. Adoption rates might have been greater for 'Fougamou', a cooking banana with lower bunch weight than 'Cardaba'. However, 'Fougamou' was more stable for bunch weight, produced more pulp (the edible component of the bunch), and was closer to the plantains in dry matter content, and hence might have had a greater market potential than 'Cardaba'. Fig. 4. AMMI 1 biplot for dry matter content $(\%) . P C=$ plant crop and $\mathrm{RC}=$ ratoon crop. The horizontal line The plantain landraces are notably higher
indicates the zero ICA 1 score while the vertical line represents the dry matter content grand mean. Codesin dry matter content, but also generally disused for cultivar or hybrid designation are given in Table 1.

play longer growth cycles, than other Musa genomic groups (Baiyeri et al., 1999). The introgression of genes for resistance to black

produced large bunches. This was associated with relatively high IPCA1 scores (Fig. 2).

Pulp weight was also lowest in the plantains, but two genotypes, 'Agbagba' and 'Obino l'ewai', had near-zero IPCA1 scores, reflecting their stability for this trait, in comparison with other genotypes (Fig. 3). The dessert banana 'Valery' also had a near-zero IPCA1 score that was associated with a greater pulp yield than for plantains. Most cooking banana landraces expressed relatively high pulp yield, but none was stable for this trait. Among the tetraploid hybrids, only 'FHIA3' expressed both high pulp yield and near-zero IPCA1 score. However, one dessert banana hybrid ('FHIA1') and three plantain hybrids ('PITA1', 'PITA2', and 'PITA7') had relatively high pulp weight associated with |IPCA1| scores $\leq 0.5$.

Dry matter content appeared to be more stable across environments than bunch weight and pulp weight, regardless of ploidy or genomeSigatoka disease from wild diploid bananas classification (Fig. 4). Among the triploidinto the plantain germplasm may shorten the landraces, only 'KM5', a dessert banana, mark-crop cycle of the hybrids, but dry matter conedly departed from the zero IPCA1 score;tent is also reduced (Vuylsteke et al., 1997). among the tetraploid hybrids, large deviationsNonetheless, plantain hybrids 'PITA1', from the zero score were observed for two'PITA2', and 'PITA7' combined high bunch cooking banana hybrids ('BITA2' andweight with highdry mattercontent. The former 'FHIA3') and one plantain hybrid ('FHIA21').characteristic resulted from a genuine increase in dry matter production. This contrasted with the high bunch weight in dessert and cooking bananas that was primarily due to increased

The occurrence and magnitude of geno-water content.

type $\times$ environment interaction complicate Ortiz (1997) has reported on the phenoselection of appropriate cultivars, particularlytypic and genetic correlation among several when this results in re-ranking of genotypesphenological and yield attributes in plantainacross environments. This type of interactionbanana hybrids. However, pulp weight and was observed in this study, suggesting thatother indicators of postharvest processing field testing of prospective cultivars should bevalue, hence market potential, were not inperformed over a larger geographical and tem-cluded in his study. Determination of the geporal scale. netic relationships between processing traits and farm gate traits could allow Musa breeders 
to construct selection indices that would facilitate multiple trait selection and enhance breeding efficiency, with respect to cultivar stability and adaptation across environments.

\section{Literature Cited}

Baiyeri, K.P., A. Tenkouano, B.N. Mbah, and J.S.C. Mbagwu. 1999. Genetic and cropping system effects on yield and postharvest characteristics of Musa species in Southeastern Nigeria. African Crop Sci. J. 7:1-7.

Cooper, M., D.E. Byth, I.H. DeLacy, and R.R Woodruff. 1993. A procedure to assess the relative merit of classification strategies for grouping environments to assist selection in plant breeding regional evaluation trials. Field Crops Res. 35:63-74.

Cooper, M. and G.L. Hammer. 1996. Plant adaptation and crop improvement. CAB Intl., Wallingford, Oxon, U.K.

Crossa, J., H.G. Gauch, and R.W. Zobel. 1990 Additive main effect and multiplicative interaction analysis of two international maize cultivar trials. Crop Sci. 30:493-500.

Dadzie, B.K. and J.E. Orchard. 1996. Postharvest criteria and methods for routine screening of banana and plantain hybrids. Intl. Network for the Improvement of Banana and Plantain. Montpellier, France.

Ferris, R.S.B, T. Adeniji, U. Chukwu, Y.O. Akalumhe, D. Vuylsteke, and R. Ortiz. 1996. Postharvest quality of plantains and cooking bananas, p. 15-22. In: R. Ortiz and M.O. Okoroda (eds.). Plantain and banana: Production and research in West and Central Africa. Intl. Inst. of Trop. Agr., Ibadan, Nigeria.
Ferris, R.S.B.,R. Ortiz,U.Chukwu, Y.O. Akalumhe, S. Akele, A. Ubi, and D. Vuylsteke. 1997. The introduction and market potential of exotic black sigatoka resistant cooking banana cultivars in West Africa. Quart. J. Intl. Agr. 36:141-152.

Gauch, H.G. 1992. Statistical analysis of regional yield trials: AMMI analysis of factorial designs. Elsevier, Amsterdam, The Netherlands.

Gauch, H.G. 1993. MATMODEL version 2.0: AMMI and related analysis for two-way data matrices. Microcomputer Power, Ithaca, N.Y.

Gauch, H.G. and R.E. Furnas. 1991. Statistical analysis of yield trials with MATMODEL. Agron. J. 83:916-920.

Kang, M.S. 1998. Using genotype-by-environment interaction for crop cultivar development. Adv. Agron. 62:199-252.

Mandel, J. 1971. A new analysis of variance model for nonadditive data. Technometrics 13:1-18.

Mobambo, K.N., F. Gauhl, D. Vuylsteke, R. Ortiz, C. Pasberg-Gauhl, and R. Swennen. 1993. Yield loss in plantain from black sigatoka leaf spot and field performance of resistant hybrids. Field Crops Res. 35:35-42.

Nyquist, W.E. 1991. Estimation of heritability and prediction of selection response in plant populations. Crit. Rev. Plant Sci. 10:235-322.

Ortiz, R. 1996. The potential of AMMI analysis for field assessment of Musa genotypes to virus infection. HortScience 31:829-832.

Ortiz, R. 1997. Genetic and phenotypic correlations in plantain-banana euploid hybrids. Plant Breeding 116:487-491.

Ortiz, R. 1998. AMMI and stability analyses of bunch mass in multilocational testing of Musa germplasm in sub-Saharan Africa. J. Amer. Soc. Hort. Sci. 123:623-627.
Ortiz, R.,P.D. Austin, and D. Vuylsteke. 1997. IITA High Rainfall Station: Twenty years of research for sustainable agriculture in the West African Humid forest. HortScience 32:969-972.

Ortiz, R., M. Iwanaga, and H.A. Mendoza. 1988. Combining ability and parental effects in $4 \mathrm{x}-2 \mathrm{x}$ crosses for potato breeding. Potato Res. $31: 643-650$.

Plucknett, D.L, N.J.H. Smith, J.T. Williams, and N.M. Anishetty. 1987. Gene-banks and the world's food. Princeton Univ. Press, N.J.

Robinson, J.C. 1996. Bananas and plantains. CAB Intl., Wallingford, Oxon, U.K.

Ruhigwa, B.A, M.P. Gichuru, B. Mambani, and N.M. Tariah. 1992. Root distribution of Acio barteri, Alchornea cordifolia, Casia siamea and Gmelina arborea in an acid ultisol. Agroforestry Systems 19:67-78.

Sánchez Nieva, F., I. Hernández, G. Colom Covas, R. Guadalupe Luna, N. Diaz, and C.B. Vinas. 1968. A comparative study of some characteristics of two plantain cultivars which affect yields and product quality. J. Agr. Univ. Puerto Rico 52:323-338.

Simmonds, N.W. 1962. The evolution of the bananas. Longman, Green, and Co., London, U.K.

Stover, R.H. and N.W. Simmonds. 1987. Bananas, 3rd ed. Longman, London, U.K.

Swennen, R. 1990. Plantain cultivation under West African conditions-A reference manual. Intl. Inst. of Trop. Agr., Ibadan, Nigeria.

Vuylsteke, D., R. Ortiz, R.S.B. Ferris, and J.H. Crouch. 1997. Plantain improvement. Plant Breed. Rev. 14:267-320.

Zobel, R.W., M. J. Wright, and H.G. Gauch, Jr. 1988. Statistical analysis of a yield trial. Agron. J. 80:388-393. 